\title{
Should Starch Metabolism Be a Key Point of the Climacteric vs. Non-climacteric Fruit Definition?
}

\author{
Christian Chervin* \\ University of Toulouse, Toulouse INP, INRA, CNRS, ENSAT, GBF, LRSV, Castanet-Tolosan, France
}

Keywords: starch, synthesis, degradation, fleshy fruit, climacteric definition

\section{INTRODUCTION}

The usual definition of the difference between climacteric and non-climacteric fruit relies on the fact that climacteric fruit ripens with concomitant increases of respiration and ethylene production, whereas barely any change in these two metabolisms occurs in non-climacteric fruit (Cherian et al., 2014). These authors list a series of climacteric fruit, such as tomato, banana, apple and mango, and a series of non-climacteric fruit such as strawberry, melon and grape. I think melon is a particular case, with climacteric and non-climacteric cultivars (Obando-Ulloa et al., 2009; Saladié et al., 2015), and this will not be detailed here. Other fruits have such climacteric and non-climacteric cultivars within a same species, for example Asian pears (Itai and Fujita, 2008) and plums (Minas et al., 2015). There have been many other reviews and articles over the last decade, regarding the differences between climacteric and non-climacteric fruit classes (Paul et al., 2012; Osorio et al., 2013; Saladié et al., 2015; Farcuh et al., 2017; Fuentes et al., 2019), but none pointed out that starch accumulation or breakdown could be a cornerstone in the definition of these two fruit classes.

A quick data review, as detailed below, shows that most climacteric fruit accumulate starch before the onset of ripening, then starch is broken down to soluble sugars after the inception of ripening, whereas in the non-climacteric fruit the starch content drops very rapidly after anthesis, and they accumulate mainly soluble sugars throughout development and ripening. This big difference leads to different harvest strategies: climacteric fruit can be picked early, and the starch reserve will be converted to sugars over postharvest stages, whereas the non-climacteric fruit should be picked when the desired soluble sugar level is reached.

However, starch metabolism is rarely mentioned as a key difference between climacteric and non-climacteric fruit. Osorio et al. (2012) suggested that the regulation of starch synthesis may be part of this difference, when comparing climacteric (tomato) and non-climacteric (pepper) fruit transcripts around the onset of ripening.

Thus, I will first list starch contents in some climacteric and non-climacteric fruit, then I will This article was submitted to Crop and Product Physiology, a section of the journal

Frontiers in Plant Science

Received: 22 September 2020 Accepted: 13 November 2020 Published: 02 December 2020

Citation:

Chervin C (2020) Should Starch

Metabolism Be a Key Point of the Climacteric vs. Non-climacteric Fruit review rapidly the starch synthesis and the starch breakdown metabolisms in plants, and finally I will discuss research perspectives.

\section{STARCH LEVEL OVER FRUIT DEVELOPMENT IN VARIOUS SPECIES}

The following data are summarized in Figure 1A. In tomato, the starch content rises up to $10 \mathrm{mg}$ to $20 \mathrm{mg} / \mathrm{g}_{\mathrm{FW}}$ up to breaker stage, then drops around $0.1 \mathrm{mg} / \mathrm{g}_{\mathrm{FW}}$ when the fruit ripens (Schaffer and Petreikov, 1997; Petreikov et al., 2009; Hou et al., 2019). In banana, the starch content is relatively high reaching $100-300 \mathrm{mg} / \mathrm{g}_{\mathrm{FW}}$ before harvest, while the starch content in ripe fruit drops below 150 to $<10 \mathrm{mg} / \mathrm{g}_{\mathrm{FW}}$, depending the cultivar (Cordenunsi-Lysenko et al., 2019). In apple flesh the 
A

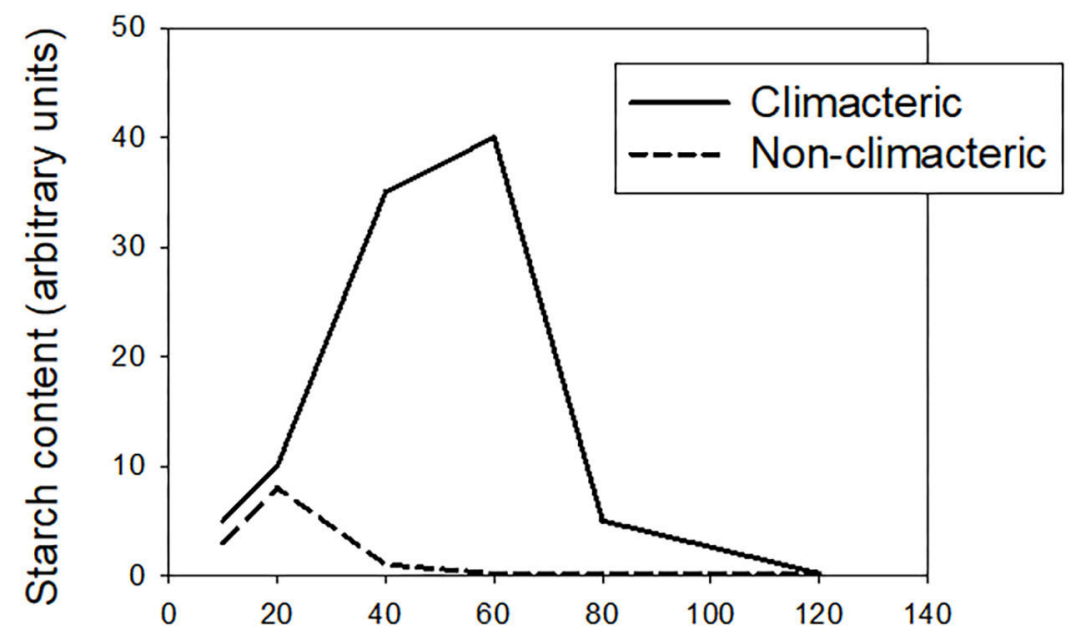

Time after anthesis (arbitrary units)
B

\section{Starch synthesis}

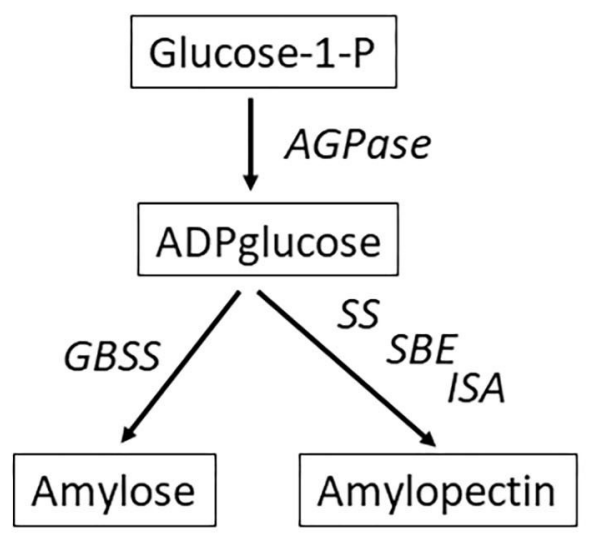

Starch breakdown

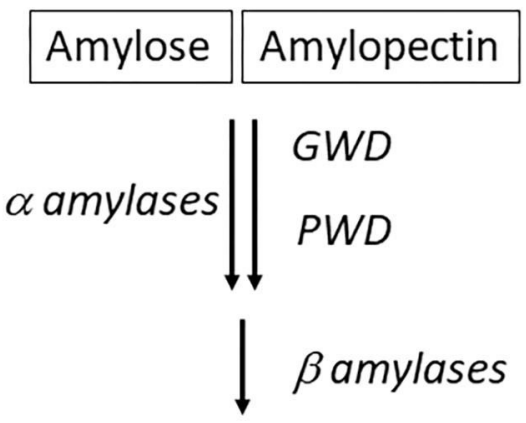

Maltose

FIGURE 1 | (A) Changes in starch accumulation over fruit development and ripening in climacteric and non-climacteric fruit (adapted from various references listed in the text). (B) Main steps of starch synthesis and degradation in plants, AGPase stands for ADP-glucose pyrophosphorylase, GBSS for granule-bound starch synthase, SS for starch synthase, SBE for starch branching enzyme, ISA for isoamylase, GWD for glucan water dikinase, and PWD for phosphoglucan water dikinase (adapted from various references listed in the text).

starch content can reach $20-25 \mathrm{mg} / \mathrm{g}_{\mathrm{FW}}$ 90-120 days after anthesis, according the cultivars, then drops to levels below 0.5 $\mathrm{mg} / \mathrm{g}_{\mathrm{FW}}$ in ripe fruit (Ohmiya and Kakuishi, 1990; Brookfield et al., 1997). In mango the starch accumulates up to $60 \mathrm{mg} / \mathrm{g}_{\mathrm{FW}}$ at harvest, then drops to $<5 \mathrm{mg} / \mathrm{g}_{\mathrm{FW}}$ in 10 days of ripening (Simão et al., 2014).

Regarding the non-climacteric fruit, the pattern of starch content is clearly different. In strawberry the starch content drops rapidly from 15 to $<1 \mathrm{mg} / \mathrm{g}_{\mathrm{FW}} 20$ days after anthesis in developing fruit (Souleyre et al., 2004). In grape berry flesh, the starch accumulation over development and ripening is very limited, with a rapid drop from $0.5 \mathrm{mg} / \mathrm{g}_{\mathrm{FW}}$ to stable concentrations below $0.1 \mathrm{mg} / \mathrm{g}_{\mathrm{FW}}$, as soon as the berry reaches 20 days after anthesis up to harvest (Zhu et al., 2017). However, these authors showed that both strawberries and grapes accumulated large amount of soluble sugars, instead of starch, during the fruit development period.

\section{STARCH SYNTHESIS AND BREAKDOWN IN PLANTS}

Starch synthesis in plants has been reviewed (Kötting et al., 2010; Geigenberger, 2011; Pfister and Zeeman, 2016) among other works. Starch is composed of amylose and amylopectin fractions. It is a relatively simple pathway, as shown in 
Figure 1B, with three main steps: (1) production of ADPglucose from glucose-1-P by an ADPglucose pyrophosphorylase (AGPase), (2) production of amylose from ADP-glucose by a granule-bound starch synthase (GBSS), or (3) production of amylopectine fromADP-glucose by a series of reactions driven by starch synthase (SS), starch branching enzyme (SBE) and isoamylase-type debranching enzyme (ISA), sometimes called debranching enzyme.

Linked to the starch synthesis, Centeno et al. (2011) showed that alterations of malate metabolism in tomatoes led to altered levels of starch accumulation, though regulation of the redox status of the AGPase.

Starch degradation is more complex than starch synthesis, as it follows different pathways according to the plant organ where they occur (Kötting et al., 2010; Zeeman et al., 2010). The glucose polymers in vivo are degraded mainly by $\beta$-amylases and to a lesser extent by $\alpha$-amylases. The activities of these latter are regulated by the level of phosphorylation or de-phosphorylation of the glucose chains, performed by glucan water dikinase (GWD) and phosphoglucan water dikinase (PWD). For detailed mechanisms, see the review articles cited above.

\section{DISCUSSION AND PERSPECTIVES}

From general knowledge, outlined in Figure 1A, it is clear that starch accumulation pattern is different between climacteric and non-climacteric fruit classes. This could be further reinforced by studies on a broader range of fleshy fruit, to confirm that starch accumulation pattern is an essential difference between both fruit classes. As mentioned above, Osorio et al. (2012) suggested that starch synthesis may be a key step differentiating the climacteric from the non-climacteric, thus I performed a quick literature search on this step, regarding some climacteric and non-climacteric fruit.

Robinson et al. (1988) showed that AGPase activity in developing tomatoes was closely related to starch accumulation, for which Petreikov et al. (2009) showed this enzyme is a limiting step. In banana, there is a study focused on the AGPase family, with phylogeny and expression details (Miao et al., 2017), but there is only one stage of fruit development. AGPase proteins

\section{REFERENCES}

Brookfield, P., Murphy, P., Harker, R., and MacRae, E. (1997). Starch degradation and starch pattern indices; interpretation and relationship to maturity. Postharvest Biol. Technol. 11, 23-30. doi: 10.1016/S0925-5214(97)01416-6

Centeno, D. C., Osorio, S., Nunes-Nesi, A., Bertolo, A. L., Carneiro, R. T., Araújo, W. L., et al. (2011). Malate plays a crucial role in starch metabolism, ripening, and soluble solid content of tomato fruit and affects postharvest softening. Plant Cell 23, 162-184. doi: 10.1105/tpc.109.072231

Cherian, S., Figueroa, C. R., and Nair, H. (2014). 'Movers and shakers' in the regulation of fruit ripening: a cross-dissection of climacteric versus nonclimacteric fruit. J. Exp. Bot. 65, 4705-4722. doi: 10.1093/jxb/eru280

Cordenunsi-Lysenko, B. R., Nascimento, J. R. O., Castro-Alves, V. C., Purgatto, E., Fabi, J. P., and Peroni-Okyta, F. H. G. (2019). The starch is (not) just another brick in the wall: the primary metabolism of sugars during banana ripening. Front. Plant Sci. 10:391. doi: 10.3389/fpls.2019.00391 were found in all developing stages of strawberry (Souleyre et al., 2004), but no starch accumulated. In grapes, the data about starch accumulation in fruit is scarce. There is one study about AGPase expression in inflorescences (Sawicki et al., 2015), but not in berries. What about in other fleshy fruit species?

Nowadays with increasing availability of large data sets, regarding the transcriptomes or the proteomes, further research regarding the starch synthesis pathway could be initiated comparing some model fruit. Regarding tomato, one tool has recently been published, TomExpress (Zouine et al., 2017). It regroups a wide array of RNAseq studies, and allows to search for expression patterns of all tomato genes. For banana, there is the Banana Genome Hub, containing a transcriptomics search tool (Droc et al., 2013). For apple, there is a similar web site, called AppleMDO, published recently by Da et al. (2019). For collecting grape RNAseq data and making them searchable, a new platform has been created, called GrapeRNA (Wang et al., 2020) and for Citrus sinensis a recent data basis has been created too (Feng et al., 2019). Mining such databases and others, for other fruit species, with a focus on the few starch synthesis genes, by comparing developing stages of climacteric and non-climacteric fruit, would probably generate new insight into differences between these two fruit classes, and may reinforce the fact that starch should be a cornerstone of the definition of climacteric vs. non-climacteric. This could lead to new research.

Regarding starch degradation, the mining of such large data sets may also reveal some differences between these two fruit classes, that have not yet been studied. I believe more is to be uncovered in the coming decade, regarding starch metabolism in climacteric vs. non-climacteric fruit.

\section{AUTHOR CONTRIBUTIONS}

CC wrote the article and created the illustration.

\section{ACKNOWLEDGMENTS}

Thanks to the Toulouse Institut National Polytechnique for support in research activities. 
Geigenberger, P. (2011). Regulation of starch biosynthesis in response to a fluctuating environment. Plant Physiol. 155, 1566-1577. doi: 10.1104/pp.110.170399

Hou, L. Y., Ehrlich, M., Thormählen, I., Lehmann, M., Krahnert, I., Obata, T., et al. (2019). NTRC plays a crucial role in starch metabolism, redox balance, and tomato fruit growth. Plant Physiol. 181, 976-992. doi: 10.1104/pp.19.00911

Itai, A., and Fujita, N. (2008). Identification of climacteric and nonclimacteric phenotypes of asian pear cultivars by APS analysis of 1aminocyclopropane-1-carboxylate synthase genes. HortSci. 43, 119-121. doi: 10.21273/HORTSCI.43.1.119

Kötting, O., Kossmann, J., Zeeman, S. C., and Lloyd, J. R. (2010). Regulation of starch metabolism: the age of enlightenment? Curr. Opin. Plant Biol. 13, 321-329. doi: 10.1016/j.pbi.2010.01.003

Miao, H., Sun, P., Liu, Q., Liu, J., Xu, B., and Jin, Z. (2017). The AGPase family proteins in banana: genome-wide identification, phylogeny, and expression analyses reveal their involvement in the development, ripening, and abiotic/biotic stress responses. Int. J. Mol. Sci. 18:1581. doi: 10.3390/ijms18081581

Minas, I. S., Font i Forcada, C., Dangl, G. S., Gradziel, T. M., Dandekar, A. M., and Crisosto, C. H. (2015). Discovery of non-climacteric and suppressed climacteric bud sport mutations originating from a climacteric Japanese plum cultivar (Prunus salicina Lindl.). Front. Plant Sci. 6:316. doi: 10.3389/fpls.2015.00316

Obando-Ulloa, J. M., Jowkar, M. M., Moreno, E., Souri, M. K., Martinez, J. A., Bueso, M. C., et al. (2009). Discrimination of climacteric and non-climacteric melon fruit at harvest or at the senescence stage by quality traits. J. Sci. Food Agric. 89, 1743-1753. doi: 10.1002/jsfa.3651

Ohmiya, A., and Kakuishi, N. (1990). Quantitative and apple morphological studies on fruit during development. J. Japan. Soc. Hort. Sci. 59, 417-423. doi: $10.2503 /$ jjshs. 59.417

Osorio, S., Alba, R., Nikoloski, Z., Kochevenko, A., Fernie, A. R., and Giovannoni, J. J. (2012). Integrative comparative analyses of transcript and metabolite profiles from pepper and tomato ripening and development stages uncovers species-specific patterns of network regulatory behavior. Plant Physiol. 159, 1713-1729. doi: 10.1104/pp.112.199711

Osorio, S., Scossa, F., and Fernie, A. R. (2013). Molecular regulation of fruit ripening. Front. Plant Sci. 14:198. doi: 10.3389/fpls.2013.00198

Paul, V., Pandey, R., and Srivastava, G. C. (2012). The fading distinctions between classical patterns of ripening in climacteric and non-climacteric fruit and the ubiquity of ethylene - an overview. J. Food Sci. Technol. 49, 1-21. doi: 10.1007/s13197-011-0293-4

Petreikov, P., Yeselson, L., Shen, S., Levin, I., and Schaffer, A. A. (2009). Carbohydrate balance and accumulation during development of near-isogenic tomato lines differing in the AGPase-L1 allele. J. Amer. Soc. Hort. Sci. 134, 134-140. doi: 10.21273/JASHS.134.1.134

Pfister, B., and Zeeman, S. C. (2016). Formation of starch in plant cells. Cell Mol. Life Sci. 73, 2781-2807. doi: 10.1007/s00018-016-2250-x
Robinson, N. L., Hewitt, J. D., and Bennett, A. B. (1988). Sink metabolism in tomato fruit: I. Developmental changes in carbohydrate metabolizing enzymes. Plant Physiol. 87, 727-730. doi: 10.1104/pp.87.3.727

Saladié, M., Cañizares, J., Phillips, M. A., Rodriguez-Concepcion, M., Larrigaudière, C., Gibon, Y., et al. (2015). Comparative transcriptional profiling analysis of developing melon (Cucumis melo L.) fruit from climacteric and non-climacteric varieties. BMC Genomics 16:440. doi: 10.1186/s12864-015-1649-3

Sawicki, M., Ait Barka, E., Clément, C., Gilard, F., Tcherkez, G., Baillieul, F., et al. (2015). Cold-night responses in grapevine inflorescences. Plant Sci. 239, 115-127. doi: 10.1016/j.plantsci.2015.07.023

Schaffer, A. A., and Petreikov, M. (1997). Sucrose-to-starch metabolism in tomato fruit undergoing transient starch accumulation. Plant Physiol. 113, 739-746. doi: 10.1104/pp.113.3.739

Simão, R. A., Silva, A. P., Peroni, F. H., do Nascimento, J. R., Louro, R. P., Lajolo, F. M., et al. (2014). Mango starch degradation. I. A microscopic view of the granule during ripening. J. Agric. Food Chem. 56, 7410-7415. doi: $10.1021 /$ jf800467v

Souleyre, E. J. F., Iannetta, P. P. M., Ross, H. A., Hancock, R. D., Shepherd, L. V. T., Viola, R., et al. (2004). Starch metabolism in developing strawberry (Fragaria $x$ ananassa) fruits. Physiol. Plant 121, 369-376. doi: 10.1111/j.0031-9317.2004.0338.x

Wang, Y., Zhang, R., Liang, Z., and Li, S. (2020). Grape-RNA: a database for the collection, evaluation, treatment, and data sharing of grape RNA-Seq datasets. Genes 11:315. doi: 10.3390/genes11030315

Zeeman, S. C., Kossmann, J., and Smith, A. M. (2010). Starch: its metabolism, evolution, and biotechnological modification in plants. Annu. Rev. Plant Biol. 61, 209-234. doi: 10.1146/annurev-arplant-042809-112301

Zhu, X., Zhang, C., Wu, W., Li, X., Zhang, C., and Fang, J. (2017). Enzyme activities and gene expression of starch metabolism provide insights into grape berry development. Hortic. Res. 4:17018. doi: 10.1038/hortres.2017.18

Zouine, M., Maza, E., Djari, A., Lauvernier, M., Frasse, P., Smouni, A., et al. (2017). TomExpress, a unified tomato RNA-Seq platform for visualization of expression data, clustering and correlation networks. Plant J. 92, 727-735. doi: $10.1111 /$ tpj.13711

Conflict of Interest: The author declares that the research was conducted in the absence of any commercial or financial relationships that could be construed as a potential conflict of interest.

Copyright (C) 2020 Chervin. This is an open-access article distributed under the terms of the Creative Commons Attribution License (CC BY). The use, distribution or reproduction in other forums is permitted, provided the original author $(s)$ and the copyright owner(s) are credited and that the original publication in this journal is cited, in accordance with accepted academic practice. No use, distribution or reproduction is permitted which does not comply with these terms. 